\title{
Historical Reflections on Culinary Globalization in East Asia
}

The articles in this special issue on East Asian food present a view of how the proponents of traditional culinary practices are encountering the forces of globalization and change today through the examples of Chinese pork banquets, Okinawan clams, the styles of preparation called "Kyoto cuisine" and the hansik of the Korean court, government-sponsored food education (shokuiku) programs in Japan, and culinary documentaries broadcast on state-owned television in China. All of these references to "tradition" are efforts to connect people through food to a locality, whether it is to the ancestral home, a region, or the nation.

In these examples, food is the glue used to try to join people to a sense of place, but food is an object, not a subject. Anthropologist Nicholas Thomas (1991: 4) notes, "objects are not what they were made to be but what they have become." In other words, an object's meaning is not inherent or stable, a point especially true where food is concerned. Objects need to be physically (and intellectually) processed before they can be consumed as food. One could go so far as to ask: When does something become food? Does food appear when a pig is butchered or a clam is harvested? Or, is the recognition of food something more sensual that occurs between the teeth? An object will never become "food" if we spit it out.

From that perspective, it can be said that nothing is intrinsically Korean, Taiwanese, or Chinese in a given food except in the way it is identified as such, and that may have little to do with the degree to which that food was or is actually consumed in a given country. Emiko Ohnuki-Tierney (1993) noted that rice was an enduring metaphor for Japanese identity despite the fact that a large portion of the population never consumed rice as a main staple. Indeed, from its introduction in the first or second millennia BCE until the seventeenth century CE, rice supplied only around 25 percent of the food needs of the population; nonetheless, starting in the seventh century, rice became the medium for taxation and exchange, and thus was the focus of state records that failed to include other types of grains and gathered foods which were not taxed but comprised a larger portion of the diet (von Verschuer 2016). Even when rice became a more prominent staple in the first half of the twentieth century, the heterogeneous ways of consuming rice, which varied depending on the degree to which it was milled (brown, white, or in between), how it was cooked (boiled, steamed, or both), and what it was mixed with (other grains, tubers, or vegetables), meant that Japanese people experienced rice in their everyday lives as much as a marker of differences in terms of gender, status, wealth, and locality than as a singular grain that provided a common sense of national identity (Rath 2016).

It is thus problematic to assume that the signifier of national identity in certain foods outweighs all other meanings. A recent study examined recipes submitted to Japanese websites for "Japanese" pasta dishes defined by their use of miso, soy sauce, cod roe, and other native ingredients. The study concluded that "the recipes testified that ordinary people take part in the creation and maintenance of national identity through their everyday acts" (Ichijo and Ranta 2016: 41). The assumption that uploading a "Japanese" recipe to a website is a way to reaffirm national identity should also promote inquiry into the identity formation of a Japanese who submits a recipe to the same website for Kansas City-style BBQ sauce. If the recipe includes soy sauce, then one could point to the ingredient to say that it expresses "Japaneseness," even if it is only a tablespoon's worth - except that a tablespoon of soy sauce is what the recipe for Kansas City-style BBQ sauce on the Food Network website also suggests. My friends in Kansas would never defer to the Food Network to teach them about Kansas City BBQ. They would instead turn to famous local restaurants like Arthur Bryant's or Gates (or allude to their own "secret" recipes). Both the Food Network and restaurants have a financial stake in claiming the superiority of their $\mathrm{BBQ}$ recipes, but the motivation of the Japanese author who uploads a Kansas City BBQ recipe to a Japanese website 
is more difficult to ascertain, especially regarding that person's degree of identification with Kansas City. Answering that question requires knowing more about that person than just the recipe he or she wrote.

Beyond the use of certain "national" ingredients, the authors of the study of Japanese pasta recipes also identify convenience, health, comfort, use of leftovers, and seasonality as markers of "Japanese" cuisine, but these elements could be said to be true for all good cooking (Ichijo and Ranta 2016: 27-42). Apart from seasonality, which was an anachronistic concept for Japanese food before the advent of refrigeration, these "Japanese" ideas resonate with Maria Child's American cookbook, The Frugal Housewife, published in 1829. Child emphasized that health, economy (more than comfort), and a preference for local over imported foods were essential to a diet conducive to the formation of an American national character (Vester 2015: 44-49). Today, Kansas City BBQ is admittedly not the healthiest food choice, but neither is sushi if "health" is measured according to the state of the world's depleted bluefin tuna stocks. In the end, if one follows the notion that everyday life is replete with banal acts that serve as reminders of the presence of the nation, it is an easy task to find examples of national identity expressed in food because everything can be read against the backdrop of national identity. Cod roe and soy sauce become more meaningful for Japanese than mostaccioli imported from Italy even if the latter is the main ingredient in a recipe. More of a challenge than discovering a pasta dish online that somehow reflects a nationality is finding one that actually tastes good.

To the untrained palate, local, national, or celebratory foods have no clearly defined taste. Children have to be told that their school lunch features hokke (Atka mackerel) from Hokkaido or indigenous rice from Taiwan. The youngsters in a household in Zhenlai County in northern Jilin Province might also demand an explanation as to why the piglet they raised to adulthood suddenly disappeared before the spring festival, especially when they are now accustomed to eating pork purchased from a butcher throughout the year.

The national and local foods in East Asia that have become rallying points against modemization and globalization are themselves products of it. In the period when all food was produced locally, such as before the late nineteenth century in Japan, the concept of a "national cuisine" or a "local food" was meaningless, and the terms were absent from the Japanese culinary lexicon. The neologisms "national cuisine" and "local cuisine" have come to be defined against the foods of other countries and in reference to the dominant meal patterns of the urban elite. Like what is referred to as "tradition," national and local cuisines are inseparable from globalization and modernity, although they have been represented as predating these forces in order to be made to stand against them.

As a historian of Japan asked to evaluate these essays by social scientists, I am interested in trying to identify the historical moments when food is identified as "local" or "national" because that suggests new recognitions and attitudes about how locality is situated in relation to the larger world. Such changes in attitude are hard to ascertain because they are so varied and diffuse; and they often fail to be recorded. Some will decry the opening of the first McDonald's in Taiwan as the arrival of globalization, foreshadowing the disappearance of indigenous food culture, but others will herald the arrival of the Big Mac as a sign of progress. All of the essays show that the voices who speak the loudest about the need to protect native foodstuffs and cooking methods have some stake in their preservation, whether they are the "skill holders" of Korean culinary tradition, the Okinawans enjoying geera clams that naicha mainlanders could never appreciate, or the advocates of Japanese "food education" who support "traditional dietary cultures" in order to counter foreign food imports.

Advocates defend native food by presenting it as imperiled by foreign penetration, but the exact geographies they contend they are protecting often prove hard to pin down. The practices of households in one province are sometimes given authority by being made to represent the timeless patterns of behavior of the whole of rural China. South Korean "skill holders" of hansik contend that their culinary traditions extend to North Korea even though the recipes they promote depart from the daily meals found in both countries. A wise chef can present one type of "Kyoto cuisine" to audiences abroad, but he needs to adhere to a more circumscribed version in his generations-old restaurant in the old capital. Yet, his ownership of that venerable kaiseki establishment gives him the authority to declare that his mutton recipe is a more authentic interpretation of Kyoto taste than the beef dish of a junior colleague.

Local food evokes a connection with the folkloric past that the discipline of history is particularly useful in disrupting. Comparing the uses of the past with the historical records makes it possible to test the veracity of origin stories written after the fact that give order to happenstance and make claims about the past. History does this by revealing what is omitted. Advocates of Korean court cuisine of the Joseon dynasty (1392-1910) ignore the legacy of Japanese colonialism and the division between North and South Korea by predating their hansik to an age before such historical events occurred. Backers of "food education" in Japan reference the culinary novelist Murai Gensai (1863-1927) for his use of the term shokuiku, but fail to include his more strident assertions that Japanese cuisine was unhealthy and backward compared to 
Western styles of cooking. The way that the Chinese stateowned television showcases the integration of Muslim and Tibetan dishes as examples of "people's food" elides the long-standing efforts of the Communist Party to suppress the cultural heritage of these same groups, restrict their religious practices, and limit their participation in civil society.

The global flows of foods that have become such causes for alarm today are much older than what is called the age of globalization and in fact helped to give rise to the "indigenous" food cultures many seek to enshrine and preserve against international influence. The maize for the "monotonous" corn porridge that was a staple in northern China, the chili peppers essential for kimchi, and the purple sweet potatoes of Okinawa, which are even featured in the "local" variety of KitKat chocolate bar for sale there, are all products of the Columbian Exchange, brought by Europeans to East Asia from the New World in the early modern period. The Muslim presence in China is older still, dating back some 1,400 years and continually enriched from that date through contacts via the Silk Road and by sea.

In Japan, the legacy of these global exchanges is preserved linguistically in a form that acknowledges their foreignness but simultaneously obscures their correct points of origin, which may not have been well understood. Peppers, aka "Chinese mustard" (tōgarashi), and corn, aka "Chinese maize" (tommorokoshi), were identified with China $(t \bar{o})$ instead of the Americas, giving foreign foods a patina of familiarity when they arrived in Japan in the sixteenth century, but at the same time distancing them from current external political forces. The designation " $t \bar{o}$ " references China's Tang dynasty (618-907), a golden age against which then contemporary China could be measured as lacking. Sweet potatoes arrived first in Okinawa but came to Kyushu as "Chinese potatoes" (karaimo), using an alternate reading of kara for the character meaning the Tang dynasty. Outside of Kyushu, the potatoes were named satsumaimo after the Satsuma warrior domain based in Kyushu that controlled the Ryukyu kingdom like a colony. Today, more than their foreignness, corn and sweet potatoes suffer in Japan for their associations with a rural diet that until the mid-196os once depended on them as staples instead of rice. Calling someone a "potato boy" (imo yarō) or a "potato sister" (imo nechan) in Japanese labels them a hick. Two varieties of peppers are included in the category of "traditional Kyoto vegetables," but their affiliation with Kyoto place names, Fushimi and Tanaka, suggests that long-term exposure to local terroir has acculturated the New World vegetables to the flavor profile of Kyoto cuisine.

Indigenous cuisine may seem bound to place and tradition, but the connections are often highly idiosyncratic. In Japan, Utsunomiya City in Tochigi Prefecture promotes Chinese dumplings as its local food and Sasebo City in Nagasaki Prefecture advertises its famous hamburgers invented in the postwar era to appeal to the crews of U.S. warships stationed there. The Japanese government defends native rice against imports, while foreign sources fulfill 95 percent of domestic demand for the soybeans used to make miso, soy sauce, natto, and so much else required for "traditional Japanese dietary cultures" (washoku). In northern China, the discourse over the necessity of home-raised pork for the spring festival diverts attention away from commodities such as mass-produced cigarettes and commercial alcohol that have become indispensable to entertaining there. Similarly, the China Central Television would rather audiences think of Lanzhou Beef Noodles as a tasty local product made from a distinct broth than as a recipe defined according to Islamic dietary laws. Gastro-diplomatic discourse and the rhetoric of local cuisine provide recipes for identifying a few foods as indigenous in order to try to shape the habits of the people who are told they should eat them; but in evaluating any recipe one must consider the sourcing of all of the ingredients, their relative amounts, and what has been left out.

\section{REFERENCES}

Ichijo, Atsuko, and Ronald Ranta. 2016. Food, National Identity and Nationalism: From Everyday to Global Politics. New York: Palgrave Macmillan.

Ohnuki-Tierney, Emiko. 1993. Rice as Self: Japanese Identities through Time. Princeton, NJ: Princeton University Press.

Rath, Eric C. 2016. Japan's Cuisines: Food, Place and Identity. London: Reaktion Books.

Thomas, Nicholas. 1991. Entangled Objects: Exchange, Material Culture, and Colonialism in the Pacific. Cambridge, MA: Harvard University Press.

Vester, Katharina. 2015. A Taste of Power: Food and American Identities. Berkeley: University of California Press.

von Verschuer, Charlotte. 2016. Rice, Agriculture, and the Food Supply in Premodern Japan. Translated and edited by Wendy Cobcroft. London and New York: Routledge. 